\title{
An Introductory Laboratory Course for Electrical Engineering Majors
}

\section{Dr. Chiu Choi, University of North Florida}

Dr. Choi is a professor in the Department of Electrical Engineering at the University of North Florida. He earned his Master's and Ph.D. degrees in electrical and computer engineering at the University of California, Santa Barbara. Dr. Choi can be reached at cchoi@unf.edu. 
An Introductory Laboratory Course for Electrical Engineering Majors 


\title{
An Introductory Laboratory Course for Electrical Engineering Majors \\ Chiu H. Choi \\ University of North Florida
}

\begin{abstract}
$\underline{\text { Abstract }}$
A new set of laboratory experiments were developed for our electrical engineering majors taking the first laboratory course in our curriculum. The new set of laboratory experiments provided training in the operation of laboratory instruments, verification of circuit theorems, advanced circuit simulation techniques, applications of operational amplifiers, and the design of signal conditioning circuits. In these new laboratory experiments, students derived theoretical results and simulated the circuits by Multisim. They also prototyped the hardware circuit and obtained the outputs by laboratory instruments. These students also compared these experimental results with theoretical and simulation results and analyzed the differences. Through this process they gained valuable hands-on skills and deeper understanding of the theory and the limitations of the simulation software and the laboratory instruments. This course generated positive student responses that were indicated in the student reports and in the course evaluation.
\end{abstract}

\section{Introduction}

Generally new students enrolled in our electrical engineering program came with very little hands on laboratory experience. For example, some of them could not identify basic electronic parts such as ceramic, mylar, and electrolytic capacitors; inductors; trimpots; transistors; operational amplifiers; etc. They were not aware of capacitor and inductor letter codes. Few had used any breadboard and electronic workstation. Most of them had very little experience in operating measurement instruments such as oscilloscopes, bench top multimeters, and LCR meters. Rarely had they exposed to the iterative cycle of designing, simulating, building and testing of electrical circuits. A new set of laboratory experiments were developed for our electrical engineering majors to provide them engineering education on these topics. These experiments also prepared students for the subsequent laboratory courses such as microcontroller applications and electronics. The specific learning objectives of this laboratory course are as follows:

1. To identify basic electronic parts, to verify circuit theorems, and to acquire basic soldering skills. 
2. To gain advanced skills of circuit simulation.

3. To learn how to operate oscilloscopes, function and waveform generators, bench top multimeters, bench top power supplies, and LCR meters.

4. To learn the applications of several common electronic circuits.

5. To gain experience in the iterative cycle of designing, simulating, prototyping and testing of electronic circuits.

There are a number of laboratory manuals, e.g., [1] and [2] and other electronic laboratory manuals from various universities available online for electrical engineering majors. These laboratory manuals provide useful laboratory education; however, we do understand that we need to develop our own laboratory manual to match our own learning objectives. Therefore, we developed the new set of laboratory experiments trying to attain the above learning objectives. These experiments are described in the next section. Most of the students taking this laboratory course should have taken Circuit Analysis I that covers the theory of DC circuit analysis and the phasor method and an introduction to National Instruments Multisim simulation software. In our curriculum, electrical engineering students are to take Circuit Analysis I in their sophomore year and to take this laboratory course in their junior year. The co-requisite for this laboratory course is Circuit Analysis II and Microelectronics I. Circuit analysis II covers phasor analysis of AC circuits, power analysis, frequency response, and circuit analysis using Laplace transforms, Fourier transforms, and Fourier series. Microelectronics I covers basic microelectronic design techniques. Topics include operational amplifiers, diodes and transistor characteristics and applications, and analysis and design of amplifiers.

\section{Laboratory experiments}

\section{Laboratory 1- orientation and introduction to laboratory equipment}

During this first laboratory session, the requirements for laboratory reports and laboratory notebooks were described. One of the requirements of the laboratory reports was that in the conclusions of the report, the students should include a discussion on whether they have achieved the learning objectives for that laboratory experiment or not. The instructor would grade the entire report and would evaluate whether the learning objectives were achieved or not. 
Electrical safety precautions were discussed. All the electronic parts, wires, test leads, probes, and hand tools to be used in the entire course were distributed to the students. The list of these parts is provided in Appendix A. Those parts that the students were not familiar with were clarified for them. Resistor color code, capacitor and inductor letter codes were explained.

The students were also introduced to several pieces of equipment and instruments during this session. The first was a prototyping workstation consisting of breadboards, integrated power supplies and other features. The model is Global Specialties PB-505. Next, these students were introduced to the Rigol DG1022 function/arbitrary waveform generator. They used it to generate sinusoidal, square, and triangular signals and observed the signals on an oscilloscope, which was either a Tektronix TDS 3052 two-channel digital phosphor oscilloscope or a GW Instek GDS2104 four-channel digital oscilloscope. There was a mixture of these two models in the laboratory. Students were also introduced to a bench top power supply- model BK Precision 1670A. The last part of this session was to review Multisim for simulating electrical circuits.

Laboratory 2- using laboratory instruments (power supply, multimeter, and LCR meter) to verify circuit theorems

The objectives of this laboratory were to gain experience in using a bench-top power supply, a bench-top digital multimeter, and an LCR meter; to verify the formulas for the series and parallel combination of inductors and capacitors; and to verify linearity theorem, superposition theorem, and Thevenin theorem experimentally. The laboratory instruments used were BK Precision Power Supply 1670A, Agilent Digital Multimeter 34401A, and GW INSTEK LCR-815 LCR Meter. In the first part of this laboratory session, various capacitors were connected in series and parallel and their equivalent capacitances were measured by the LCR meter. The same was also done with inductors. Theoretical values of the series and parallel combinations of the capacitors and inductors were calculated and were compared with the measured values. Errors were computed. The formulas were verified to be within reasonable margin of error. After performing these experiments the student learned how to use an LCR meter.

In the second part of this laboratory session, the linearity theorem, superposition theorem, and Thevenin theorem were experimentally verified. To verify linearity theorem, the resistive circuit shown in Fig. 1 was built on the breadboard. The input V1 was initially at $5 \mathrm{~V}$ and was varied to 
other values. The voltage across R4 was measured for each of these input voltages by a digital multimeter (Agilent 34401A or BK Precision 5492B). The measured values were compared with the theoretical values and error was computed. The errors were within tolerable margin.

To verify superposition theorem, the resistive circuit shown in Fig. 2 was built. The voltage across R8 was measured by a digital multimeter. Next, the sources V2 and V3 were replaced by a short circuit one at a time and the voltage across R8 was measured. The sum of these two voltages were computed and compared with the first measurement with both sources present. The errors were within tolerable margin.

To verify the Thevenin's theorem, two circuits were built. The first one is shown in Fig. 3. The second one is shown in Fig. 4, which is the Thevenin equivalent of the circuit in Fig. 3. Students calculated the Thevenin voltage and resistance by themselves. Various values of R13 were used and the voltages across it in both Fig. 3 and Fig. 4 were measured. The errors were within tolerable margin.

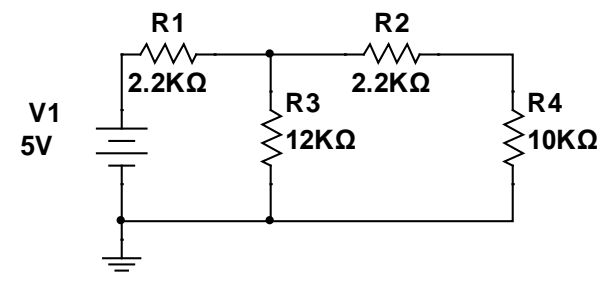

Fig. 1: circuit for verifying linearity theorem

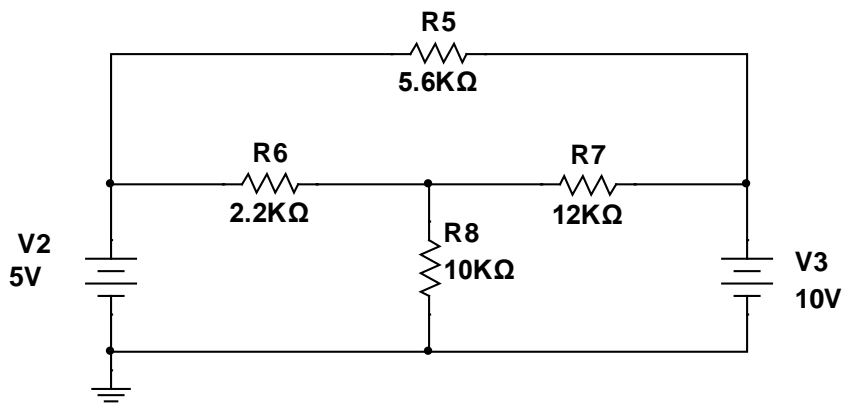

Fig. 2: circuit for verifying superposition theorem

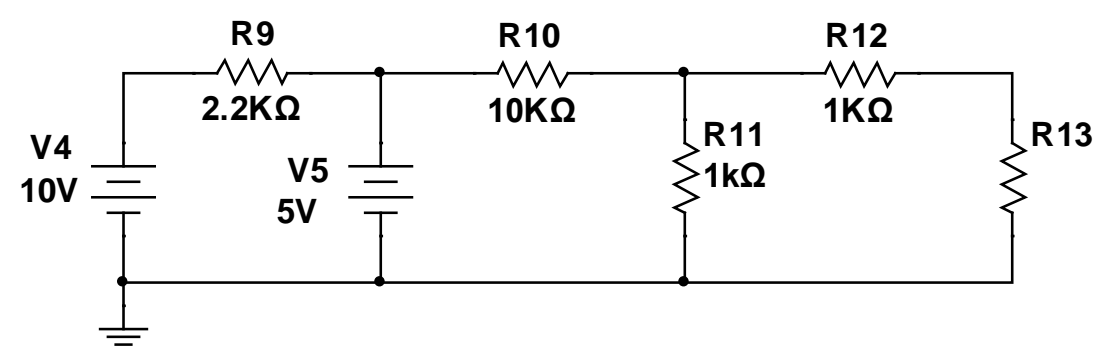

Fig. 3: circuit for verifying Thevenin’s theorem

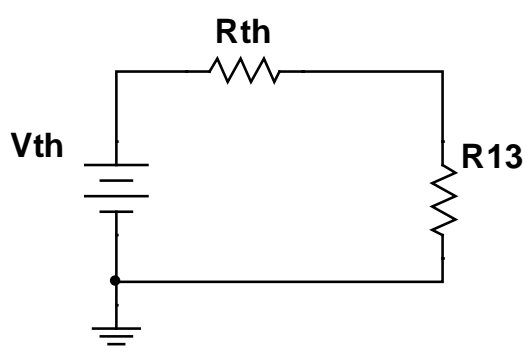

Fig. 4: Thevenin equivalent 
In the circuit in Fig. 3, it was devised that its Thevenin voltage in Fig. 4 was to be $0.455 \mathrm{~V}$ that our power supply could not be set to such small value. The intent was to challenge the students to resolve this issue. A solution was to use a scaling factor of 10 to increase the Thevenin voltage to $4.55 \mathrm{~V}$ which could be set accurately in the power supply. Linearity theorem was then used to scale the measure voltage R13 down by the same factor of 10 to get the desired result.

\section{Laboratory 3- network analysis with Multisim}

The objectives of this laboratory were to learn how to use Multisim to create and simulate circuits containing dependent sources, to learn how to use a virtual oscilloscope to observe electrical signals, and to apply circuit analysis to verify the simulation results. Illustrative examples of Multisim simulations are available within the software suite itself and also in textbooks such as [5]. During this laboratory four different circuits with controlled voltage and current sources were simulated in Multisim. Analysis-by-hand was done to verify the simulation results. These exercises

helped the students to better understand how to wire up dependent sources in a circuit and increased their understanding of the working of dependent sources.

Additional operational amplifier circuits were simulated also during this laboratory. One of the operational amplifier circuits is shown in Fig. 5. The purpose of this circuit was to check if the students could reconcile the differences between the result obtained by Multisim and those obtained by analysis-by-hand. Analyzing the circuit by hand, these students thought that the current through R4 was 5 times that of the input I1. So $0.5 \mathrm{~mA}$ was their expected answer. But Multisim did not produce such result. As seen in Fig. 5, the current through R4 was $2.35 \mathrm{~mA}$. These students were asked to investigate further by increasing the source by $0.1 \mathrm{~mA}$ every step. In each of these cases, Multisim produced the same magnitude of $2.35 \mathrm{~mA}$. The purpose of these step changes was to lead these students to realize that there was operational amplifier saturation. The answer for this discrepancy between Multisim and analysis-by-hand results was that the operational amplifier was operating in positive feedback. The solution was to reverse the inverting and non-inverting terminals. When this was done as shown in Fig. 6, the Multisim result matched the hand analysis result. Through this exercise these students learned that proper feedback to the operational amplifier should also be considered in addition to mathematical analysis. 


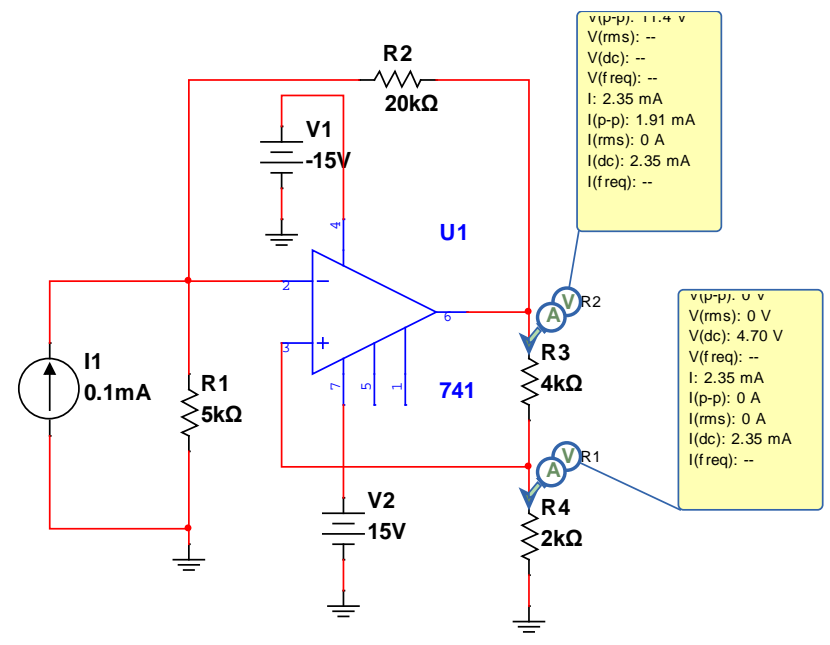

Fig. 5: operational amplifier circuit

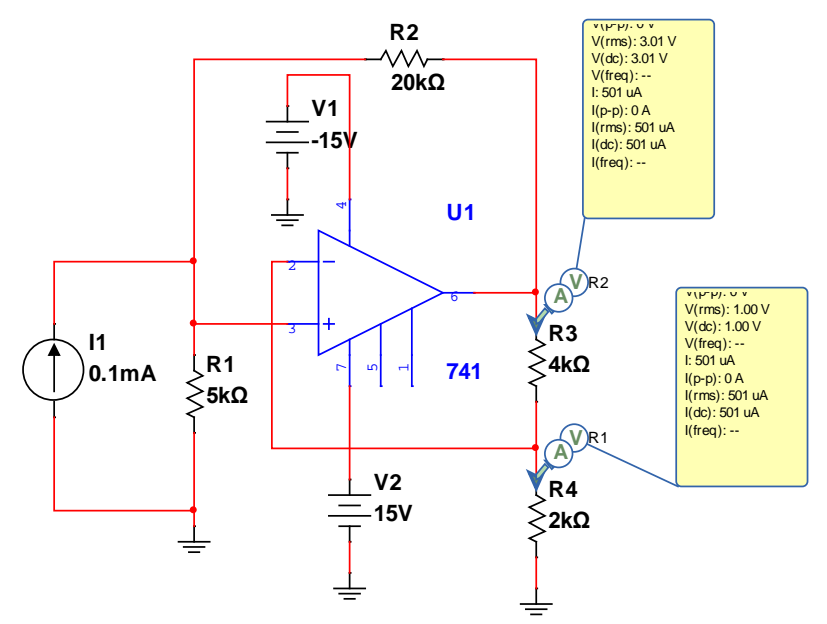

Fig. 6: revised operational amplifier circuit

Laboratory 4- signal generator, oscilloscope and RC/RLC transient responses

The objectives of this laboratory were to learn how to use a function generator to produce various electrical signals, to learn the various settings of an oscilloscope, and to use an oscilloscope to capture the transient responses of RC and RLC circuits. In the first part of this laboratory, various options for specifying the parameters of electrical signals generated by the Rigol DG-1022 Function Generator were explained. These parameters included frequency, period, amplitude, offset, high peak value, low peak value, phase difference, duty cycle, etc. Various options for setting up the oscilloscope were also introduced. These options included vertical voltage scale, horizontal time sweep rate, DC/AC coupling, triggering, measurements using cursors, etc. In the second part of this laboratory, a series RC circuit was built and was driven by a square wave generated by the function generator. The transient response of the RC circuit was captured by the oscilloscope. The time constant of the RC circuit were estimated by using the oscilloscope cursors and was compared with the theoretical value. The error was within reasonable tolerance. In the third part of this laboratory, an underdamped series RLC circuit was built and was driven by another square wave signal generated by the function generator. The transient response was captured by an oscilloscope. The signal displayed on the oscilloscope had ringing. The frequency of oscillation was measured by the oscilloscope cursors and was compared with the theoretical value. The error was again within the expected tolerance. The resistance of the RLC circuit was also changed experimentally to determine the value corresponding to the case of critically damped. . 
Through this exercise these students learned the basic skills of operating a function generator and an oscilloscope.

\section{Laboratory 5- advanced network analysis with Multisim}

The objectives of this laboratory were to learn how to use Multisim to conduct transient analysis, AC Sweep and DC Sweep analyses; to learn how to create user defined signal sources; to deduce the applications of electrical circuits by simulation; and to apply circuit analysis by hand to verify simulation results. For transient analysis, the students created rising and decaying exponential signals in Multisim, to use it as inputs to drive a RLC filter circuit and to obtain its transient response by Multisim. The same was also done but with a piecewise linear arbitrary voltage waveform. Guidance was given to these students on how to generate these waveforms in Multisim. For AC Sweep analysis, these students performed such analysis on an analog LC filter and to obtain the Bode magnitude and phase plots. Assistance was provided to these students on configuring the parameters for the AC Sweep analysis. For DC sweep analysis, these students were to perform such analysis on a voltage-to-current converter and to obtain the transfer characteristic. This laboratory provided these students insights into the various analysis capabilities offered by Multisim and that they acquired these skills that can be used to analyze advanced circuits.

\section{Laboratory 6- introduction to soldering}

The objectives of this laboratory were to gain experience in soldering electronic parts onto a printed circuit board by hand and in testing the populated printed circuit board. Before soldering the parts together, students watched video instructions for and demonstration of basic soldering. A kit (a continuity checker) was provided to each student. The kit contained an unpopulated through-hole printed circuit board and a number of electronic parts and wires to be soldered onto the board. Students populated the printed circuit board with low profile parts first and soldered these parts onto the board. Higher profile parts were placed on the board next and were soldered onto it. After soldering was completed, students tested the continuity checker with a decade box. The test result would indicate whether soldering was done correctly or not. If there were soldering errors, desoldering pumps were used to remove the solder. This laboratory was simple enough for students to learn the basic skills of soldering. More advance skills of using smaller soldering tips for surface 
mount components and the use of desoldering braid and wicks were not covered in this basic soldering laboratory session and could be considered in the future.

\section{Laboratory 7- common operational amplifier applications}

The objectives of this laboratory were to design, simulate, build and test common operational amplifier-based signal amplification circuits. The students gained experience of using datasheets for the first time in this laboratory and also learned more triggering modes for displaying a signal (consisted of mixed frequencies) steadily on the oscilloscope. In the first part of the laboratory, a circuit that amplified an input signal at a fixed gain was to be designed and built. The students used the non-inverting amplifier circuit for solving this problem ([3] and [4]). Their design was simulated in Multisim and was built on the breadboard. They verified the working of the circuit by comparing the input and output waveforms displayed on an oscilloscope. They also compared the waveforms with the simulation outputs to ensure correct results were obtained.

In the next part of the laboratory, a circuit was to be designed and built with its output equal to $2 * x_{1}(t)+x_{2}(t)$, where $x_{1}(t)=\cos (2 \pi 1000 t)$ and $x_{2}(t)=\cos (2 \pi 900 t)$. These two signals were generated by the function generator. The solution could be built with just one operational amplifier but many students used two (the summing amplifier and the inverting amplifier circuits). They simulated their design on Multisim and then built it on the breadboard. Since the difference of the two frequencies was $100 \mathrm{~Hz}$, the sum of these two signals were not displayed steadily with the default triggering setting of the oscilloscope. To obtain a steady output, the oscilloscope's trigger hold off time were adjusted until a steady waveform appeared as shown in Fig. 7. Other ways such as the single shot mode can also be used to capture one segment of the output waveform. These students became aware of these two triggering modes through this laboratory.

In the last part of the laboratory, a circuit that took the difference of two given signals was to be designed and built. The output of this circuit was to be equal to $\mathrm{x}_{1}(\mathrm{t})-2 * \mathrm{x}_{2}(\mathrm{t})$. A difference amplifier circuit as shown in Fig. 8 was used for solving this problem. This circuit was simulated in Multisim, built on the breadboard and analyzed on the oscilloscope. 


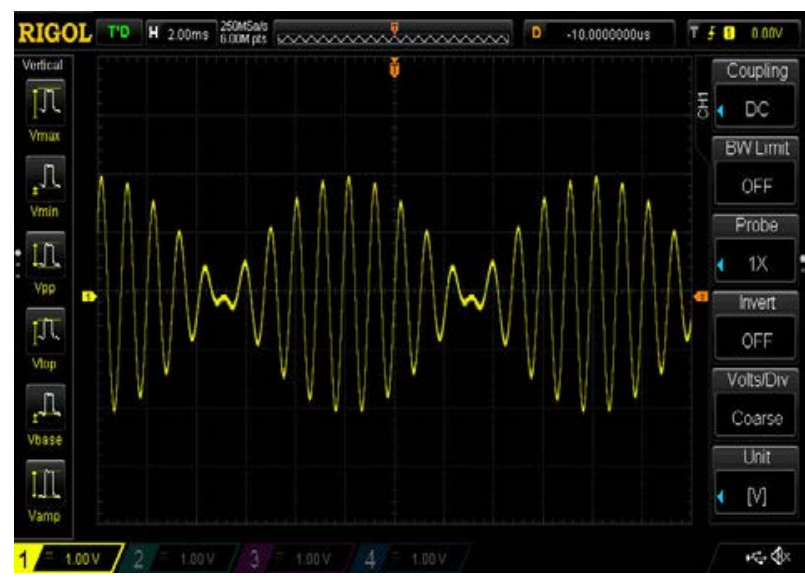

Fig 7: the sum of $\mathrm{x}_{1}(\mathrm{t})$ and $\mathrm{x}_{2}(\mathrm{t})$.

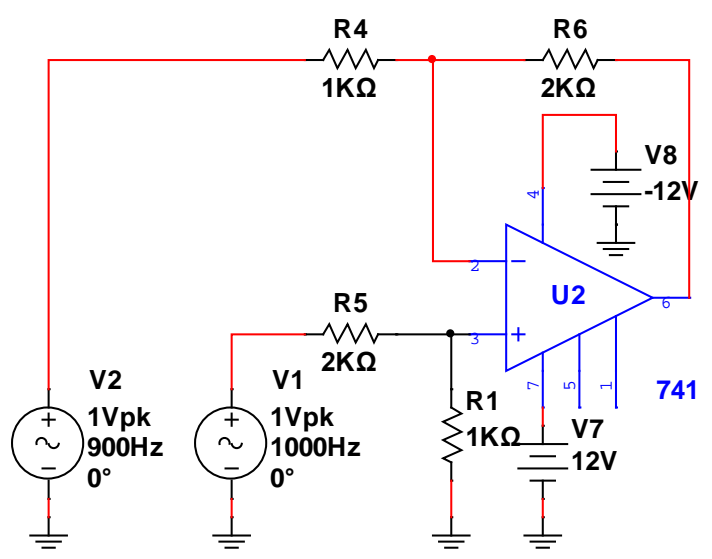

Fig. 8: difference amplifier

Through this laboratory students gained deeper understanding of the workings of operational amplifiers and special techniques of oscilloscope triggering.

\section{Laboratory 8- differentiators and integrators}

The objectives of this laboratory were to simulate, build and test operational amplifier-based differentiators and integrators. In the first part of the laboratory, the simple differentiator circuit as shown in Fig. 9 was simulated and the result is shown in Fig. 10. Oscillation was observed in the simulation. The same circuit in Fig. 9 was built on the breadboard. The input and output were captured by the oscilloscope. The input and output waveforms are shown in Fig. 11. Notice that the output signal had no oscillation. The output obtained by simulation did not match the output obtained by the oscilloscope. The expected amplitude of the square wave output was computed to be approximately $4.7 \mathrm{~V}$. The measure value was about $5 \mathrm{~V}$. The noise in the differentiator circuit shown in Fig. 9 can be improved by placing an extra resistor of small resistance in series with the capacitor.

In the second part of the laboratory, the simple integrator circuit as shown in Fig. 12 was simulated and the result is shown in Fig. 13. The integrator circuit was built on the breadboard and the input and output signals were captured by the oscilloscope. The waveforms are shown in Fig. 14. The expected peak-to-peak amplitude of the triangular output was computed from the equation $\frac{-1}{R C} \int_{0}^{t} V i(t) d t$ and was found to be $12.5 \mathrm{~V}$. The measured value on the oscilloscope was $12.2 \mathrm{~V}$. The noise in the integrator circuit can be reduced by placing an additional resistor of large resistance in parallel with the capacitor. This laboratory achieved the objectives of simulating, building and 
testing of operational amplifier-based circuits to perform the mathematical operations of differentiation and integration. It also gave the opportunity to students to recognize that the simulation results as in the case of differentiator circuit did not match the physically measured output by the oscilloscope. These students realized that they should not just rely on simulation to get the answers as the answers could be different from those obtained from the physical circuits.

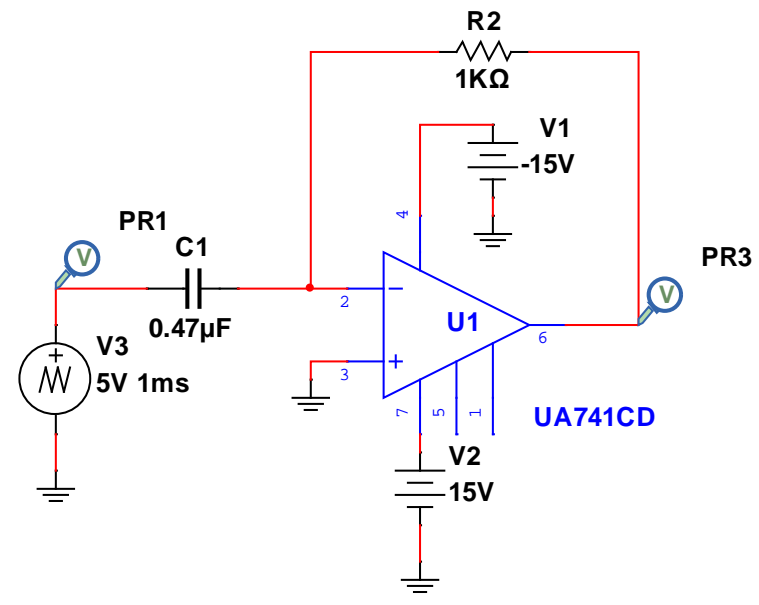

Fig 9: a differentiation circuit

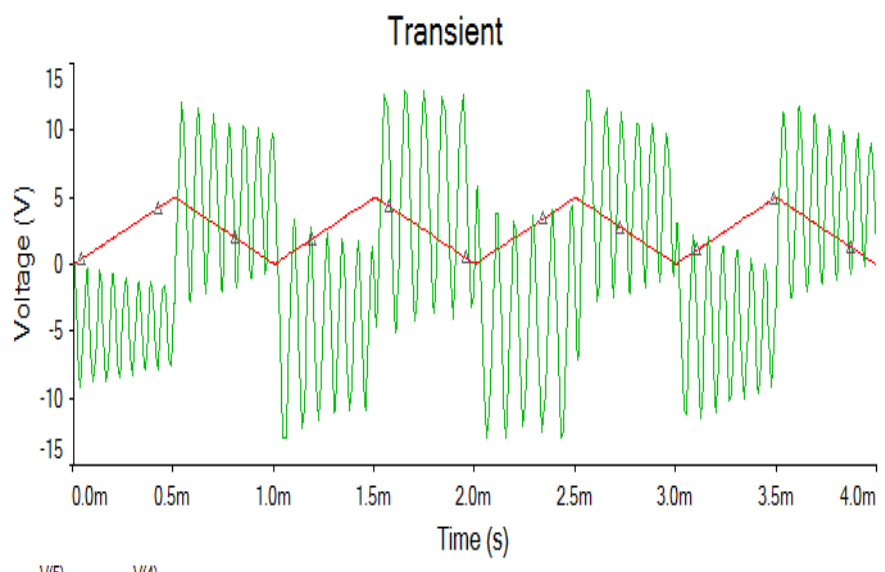

$\sqrt{V(5)} \frac{V(4)}{V(P R 1)} \nabla \frac{V(P R 3)}{V(P)}$

Fig. 10: Multisim simulation result

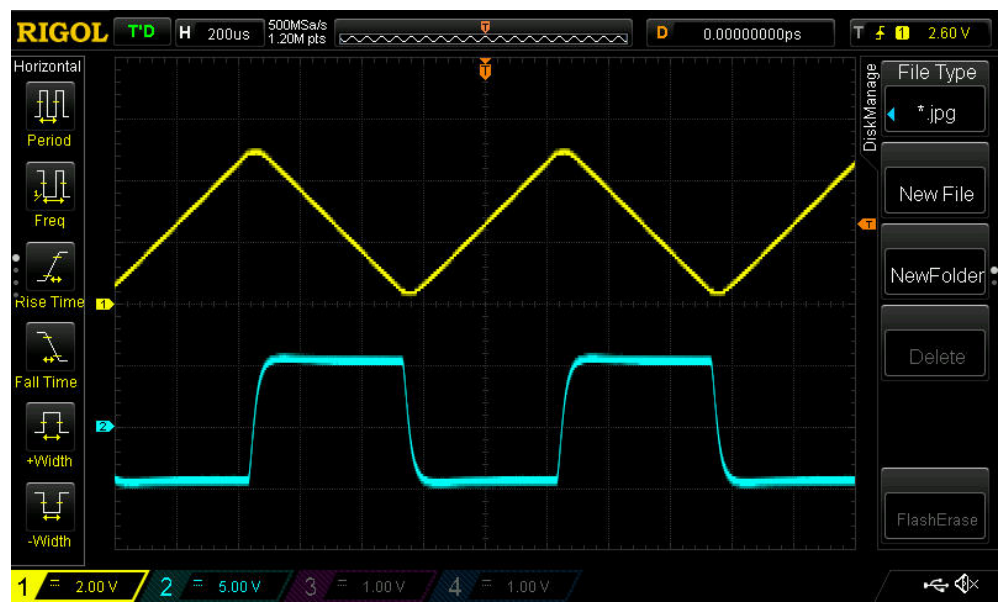

Fig. 11: differentiator input and output capture by oscilloscope 


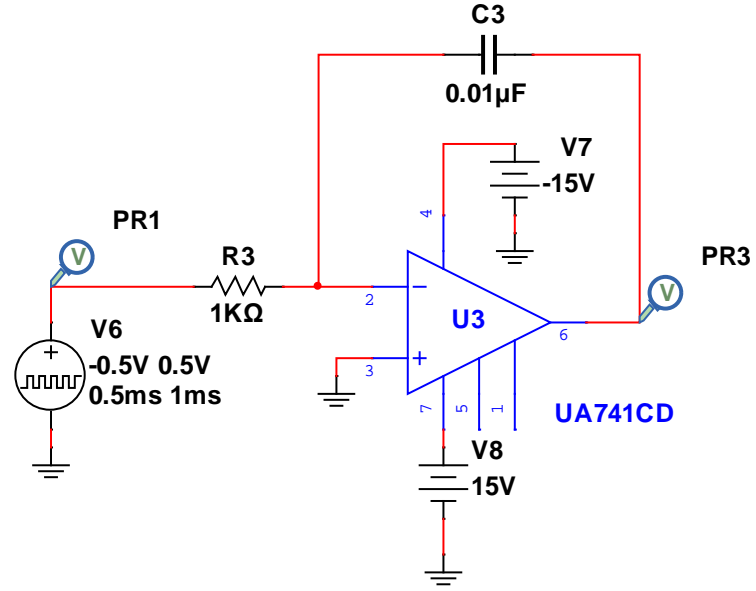

Fig 12: an integrator circuit

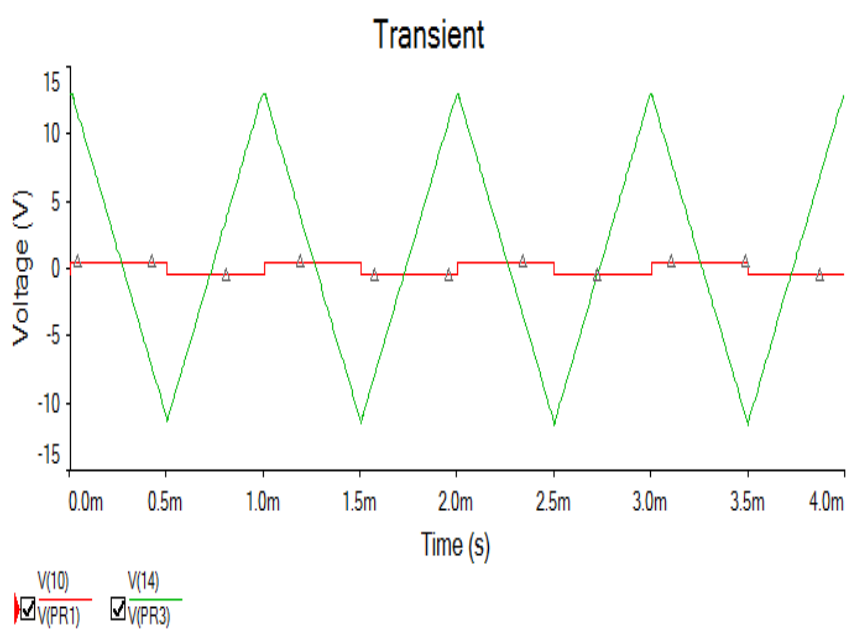

Fig. 13: Multisim simulation result

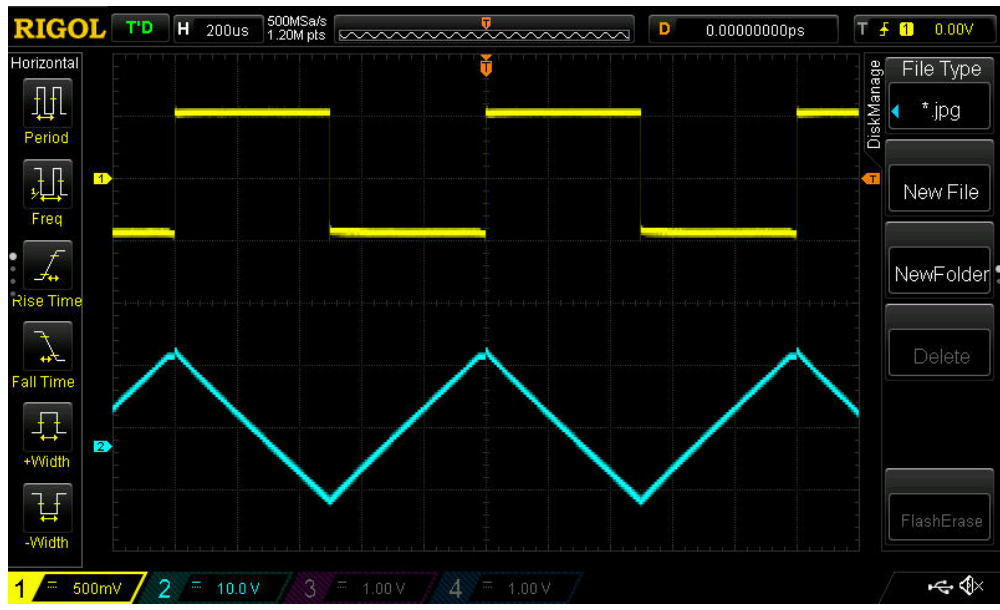

Fig. 14: differentiator input and output capture by oscilloscope

\section{Laboratory 9- design of signal conditioning circuits}

The objectives of this laboratory were to apply circuit analysis techniques to design signal conditioning circuits and to simulate, build and test these circuits. The first signal conditioning circuit to be designed by the students was a circuit that would convert an input signal with a voltage within the range of $-10 \mathrm{~V}$ to $10 \mathrm{~V}$ linearly into the range of $0 \mathrm{~V}$ to $5 \mathrm{~V}$. The first step was to develop the input/output equation, which was to be realized by the circuit. That equation was $\mathrm{V}_{\text {out }}=0.25 * \mathrm{~V}_{\text {in }}+2.5$. One of the solutions is shown in Fig. 15. Students simulated their design on Multisim and built it on the breadboard. They tested the circuit with input voltage from -10 V to 10 $\mathrm{V}$ at the step of $1 \mathrm{~V}$. The data points were plotted on the same graph for the equation 
$\mathrm{V}_{\text {out }}=0.25 * \mathrm{~V}_{\text {in }}+2.5$. Linear regression was done on the data points. The performance of the design was measured by the mean square error of the data points.

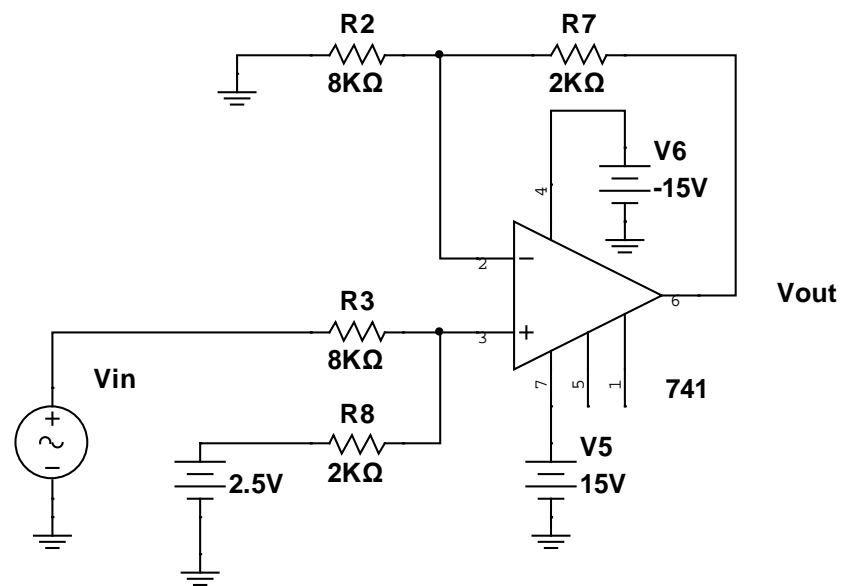

Fig. 15: operational amplifier circuit for

$$
\mathrm{V}_{\text {out }}=0.25 * \mathrm{~V}_{\text {in }}+2.5
$$

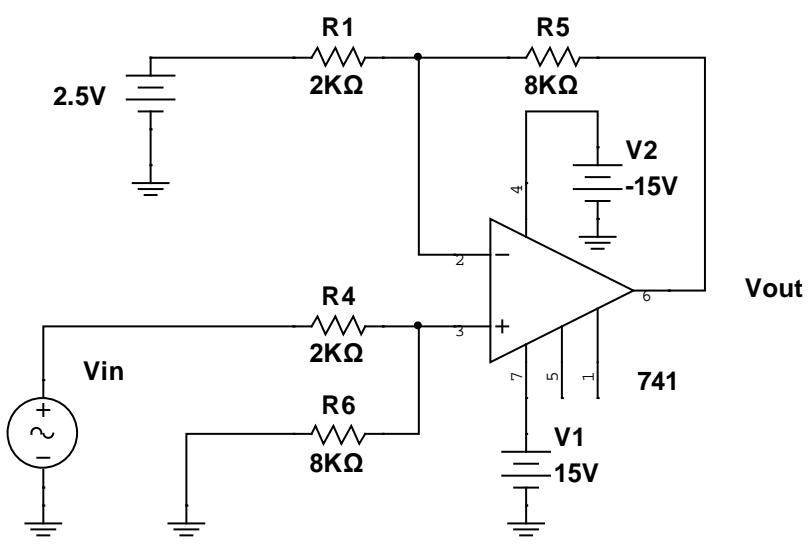

Fig. 16: operational amplifier circuit for

$$
\mathrm{V}_{\text {out }}=4 * \mathrm{~V}_{\text {in }}-10
$$

The second signal conditioning circuit to be designed was a circuit that would convert an input signal with a voltage within the range of $0 \mathrm{~V}$ to $5 \mathrm{~V}$ linearly into the range of $-10 \mathrm{~V}$ to $10 \mathrm{~V}$. The equation to be realized by the circuit was $V_{\text {out }}=4 * V_{\text {in }}-10$. One of the design is shown in Fig. 16. Students simulated their design on Multisim and built it on the breadboard. They tested the circuit with input voltage from $0 \mathrm{~V}$ to $5 \mathrm{~V}$ at the step of $0.25 \mathrm{~V}$. The data points were plotted on the same graph for the equation $\mathrm{V}_{\text {out }}=4 * \mathrm{~V}_{\mathrm{in}}-10$. Again linear regression was done on the data points and the mean square error was computed. The mean square error was used as a metric for the performance of their designs. This laboratory enhanced these students' design and troubleshooting skills and elevated their operational amplifier design techniques acquired in the previous two laboratory experiments. It also honed their circuit analysis techniques.

\section{Laboratory 10- diodes and rectifiers}

The objectives of this laboratory were to simulate on Multisim and to build on breadboard several types of rectifier circuits such as a half-wave rectifier and a full-wave bridge rectifier. The effect of capacitor on the rectified output was investigated by the students. The advantages and disadvantages of these rectifier circuits were observed and compared. In the first part of the laboratory, the students built a half-wave diode rectifier circuit with its input driven by the output 
of a step down transformer. They observed the rectified sinusoidal signal on the oscilloscope. A capacitor was then added to the circuit and its effect on the output was observed on the oscilloscope. They compared the ripple voltage and the DC level of the observed output with their expected output obtained from simulation. In the second part of the laboratory, students built a fullwave rectifier circuit and compared its performance with that of the half-wave rectifier. They observed that the ripple voltage of the full-wave rectifier was smaller than that of the half-wave but required more electronic parts to build.

This laboratory improved these students' understanding of the characteristics of diode and rectifier circuits. It provided the opportunity to learn by experiment the differences of various rectifier designs and to refine their laboratory skills of building electronic circuits and using electronic instruments. They also had the opportunity of analyzing the cost for the different designs. They realized that both the performance of a circuit and its cost were among the criteria for choosing a particular design.

\section{Laboratory 11- RLC circuits, filters, and frequency response}

The objectives for this laboratory were to investigate the frequency response of series and parallel RLC circuits and their resonant frequency experimentally. During the laboratory, the students obtained the transfer functions of two RLC circuits. They used Matlab to obtain the Bode magnitude plots and estimated the resonance frequencies. After that they built the two circuits on the breadboard. To obtain the frequency responses of these two circuits experimentally, they kept the amplitude of the input sinusoidal signal constant and measured the amplitude of the output signal over a range of input frequencies from $100 \mathrm{~Hz}$ to10 KHz. They calculated the gain and plotted the frequency responses of the two circuits and estimated the resonant frequencies from the plots. These results were compared with the Bode plots obtained by Matlab.

Through this laboratory, these students learned how to obtain the frequency response of a circuit experimentally by hand and learned how to obtain the response by engineering software. They also observed the filtering properties of the circuits from the frequency responses and the effects of the resonant frequencies. 


\section{Laboratory 12- transistor amplifiers}

The objectives of this laboratory were to investigate the biasing of a common emitter BJT amplifier and to use it to amplify a small signal. In the first part of the laboratory, the biasing circuit was simulated in Multisim and was built on the breadboard. The collector, base and the emitter voltages and currents of the biasing circuit were obtained experimentally and compared with the theoretical values. Through this exercise the student understood more about the purpose of biasing.

In the second part of the laboratory, a common emitter BJT amplifier was built and was used to amplify a small signal. The voltage amplitudes of the input and output signals were measured and the gain was calculated. The theoretical gain of this BJT amplifier was also computed and compared with the gain obtained by meaurement. The percentage error was calculated. In this laboratory these students learned how to operate a BJT transistor and gained trouble shooting skills. These skills will be useful in their next electronics laboratory course.

\section{Preliminary evaluation}

The laboratory experiments developed above were first used in fall 2016. A general student evaluation of this laboratory course was conducted at the end of that semester. The questions relevant to the quality of instructions are shown in Table 1 . The instructions were delivered to the students through the twelve laboratory handouts developed by the instructor, through the short lectures at the start of the laboratory sessions and through helping the students to solve their problems during the laboratory sessions.

Table 1: student evaluation results in fall 2016

\begin{tabular}{|l|c|c|c|c|c|c|}
\hline Item & $\begin{array}{l}\text { Strongly } \\
\text { Agree (5) }\end{array}$ & $\begin{array}{l}\text { Agree } \\
(4)\end{array}$ & $\begin{array}{l}\text { Neutral } \\
(3)\end{array}$ & $\begin{array}{l}\text { Disagree } \\
(2)\end{array}$ & $\begin{array}{l}\text { Strongly } \\
\text { Disagree (1) }\end{array}$ & Mean \\
\hline $\begin{array}{l}\text { Communication of ideas } \\
\text { and information } \\
\text { effectively. }\end{array}$ & $57.14 \%$ & $42.86 \%$ & $0.00 \%$ & $0.00 \%$ & $0.00 \%$ & 4.57 \\
\hline $\begin{array}{l}\text { Knowledgeable about the } \\
\text { subject matter. }\end{array}$ & $85.71 \%$ & $14.29 \%$ & $0.00 \%$ & $0.00 \%$ & $0.00 \%$ & 4.86 \\
\hline Stimulation of critical and & $57.14 \%$ & $42.86 \%$ & $0.00 \%$ & $0.00 \%$ & $0.00 \%$ & 4.57 \\
\hline
\end{tabular}




\begin{tabular}{|l|l|l|l|l|l|l|}
\hline creative thinking. & & & & & & \\
\hline $\begin{array}{l}\text { Setting high standards that } \\
\text { challenged the students }\end{array}$ & $71.43 \%$ & $28.57 \%$ & $0.00 \%$ & $0.00 \%$ & $0.00 \%$ & 4.71 \\
\hline
\end{tabular}

Most of these students candidly provided their voluntary comments on these twelve new laboratory experiments in their laboratory reports. Most of these comments were encouraging for this "first edition” of laboratory experiments. A brief summary of these comments follow.

- The laboratory provided basic understanding of instruments and the electronic parts that would be used in the laboratory course.

- The students learned how to construct simple circuits on a breadboard and also how to test and verify circuit theorems.

- It facilitated a good practice with how to use Multisim for simulating advanced circuits.

- The knowledge provided in this laboratory expanded these students' ability to analyze circuitry using the laboratory instruments.

- The laboratory provided the capability of Multisim in performing various analysis (transient, DC, AC, etc.).

- Even though the amount of actual soldering for this laboratory experiment was minimal but in the end, valuable skills of soldering were learned.

- This laboratory increased the understanding of operational amplifier circuit analysis and how to wire them to achieve the desired outputs.

- The experiments provided a much greater understanding of differentiators and integrators

- It took a lot of thought to build the proper conditioning circuit with the desired single operational amplifier and that lead to a better understanding of circuit design.

- By both simulating and building different types of rectifier circuits, students were able to analyze their purposes and effects.

- The frequency response laboratory helped to solidify the concepts taught during the lecture by providing experimental results to compare to theoretical results.

- The transistor amplifier laboratory was useful to learn the characteristics of a BJT and how they can be used to amplify a small input signal into a stronger output signal. 
The degree of coverage of the five objectives in Section 1 by the twelve laboratory experiments was analyzed. The result is shown in Table 2. As seen in the table, Objectives 2, 3, and 4 were fairly well covered. Objective 1 was the second least covered and a reason for that was that the students had taken only one electrical engineering course. They hadn't had the opportunity to encounter more advanced electronic parts and modules. They will be in subsequent higher level courses. Objective 5 was least covered and this will be strengthened in the future enhancement of this laboratory course.

Table 2: Mapping of the course learning objectives to the learning objectives of the laboratory experiments

\begin{tabular}{|l|l|l|l|l|l|l|l|l|l|l|l|l|l|}
\hline & Lab 1 & Lab 2 & Lab 3 & Lab 4 & Lab 5 & Lab 6 & Lab 7 & Lab 8 & Lab 9 & Lab 10 & Lab 11 & Lab 12 \\
\hline Obj. 1 & $\mathrm{x}$ & $\mathrm{x}$ & & $\mathrm{x}$ & & $\mathrm{x}$ & & & & & & \\
\hline Obj. 2 & & & $\mathrm{x}$ & & $\mathrm{x}$ & & $\mathrm{x}$ & $\mathrm{x}$ & & $\mathrm{x}$ & $\mathrm{x}$ & $\mathrm{x}$ \\
\hline Obj. 3 & $\mathrm{x}$ & $\mathrm{x}$ & & $\mathrm{x}$ & & & $\mathrm{x}$ & $\mathrm{x}$ & & $\mathrm{x}$ & & $\mathrm{x}$ \\
\hline Obj. 4 & & & $\mathrm{x}$ & & $\mathrm{x}$ & $\mathrm{x}$ & & & $\mathrm{x}$ & $\mathrm{x}$ & $\mathrm{x}$ & $\mathrm{x}$ \\
\hline Obj. 5 & & & & & & & $\mathrm{x}$ & & $\mathrm{x}$ & & & \\
\hline
\end{tabular}

The assessment of the learning objectives of each of the twelve experiments were conducted by both students and the instructor. The students were required to provide a discussion on achieving the learning objectives in the conclusion section of each of the twelve laboratory reports. The results were that they achieved all the learning objectives with documented data, graphs, circuit diagrams, etc. to support their claims of meeting all the objectives. The instructor also evaluated whether the students had achieved the learning objectives or not. The grade of the report was based on the level that the students achieved the learning objectives. A numerical grade less than 70 out of 100 indicated not meeting all of the objectives. A numerical grade of 70 to 100 indicated meeting all of the learning objectives with 70 for the case of minimally achieving all of the learning objectives and 100 for the case of very satisfactorily and with sound documented evidence. The laboratory scores are shown in Table 3. Most of the students achieved all of the learning objectives and only a small number of them did not. 
Table 3: Laboratory report scores

\begin{tabular}{|l|l|l|l|l|l|l|l|l|l|l|l|l|}
\hline & Lab 1 & Lab 2 & Lab 3 & Lab 4 & Lab 5 & Lab 6 & Lab 7 & Lab 8 & Lab 9 & Lab 10 & Lab 11 & Lab 12 \\
\hline Average & 83.23 & 91.27 & 85.54 & 82.12 & 82.92 & 92.19 & 92.19 & 89.69 & 89.19 & 89.36 & 89.92 & 94.48 \\
\hline Std. Dev. & 8.12 & 6.81 & 4.62 & 14.31 & 8.80 & 8.07 & 7.54 & 11.10 & 6.27 & 8.70 & 10.81 & 5.34 \\
\hline Maximum & 96.00 & 98.00 & 95.00 & 98.00 & 91.00 & 100.00 & 100.00 & 100.00 & 100.00 & 100.00 & 100.00 & 100.00 \\
\hline Minimum & 72.00 & 63.00 & 74.00 & 51.00 & 64.00 & 71.00 & 79.00 & 65.00 & 77.00 & 67.00 & 50.00 & 78.00 \\
\hline
\end{tabular}

Three examinations were given to these students to test their retention of the materials learned and their laboratory skills. In each examination, every student had to solve hands-on problems on their own in the laboratory. This approach could effectively assess each student's skill of building circuits, operating the laboratory instruments, and documenting the experimental data. The averages of the three examinations were 93, 81 and 89 out of 100. Their standard deviations were 6.5, 23 and 14, respectively. There was no observed anomaly in the data.

All of the data presented above were from just one semester. Additional data will be collected next time this same course is offered and further assessment will be conducted.

\section{$\underline{\text { IV. Concluding remarks }}$}

After taking this laboratory course, the students learned how to operate oscilloscopes, function generators, bench top multimeters, bench top power supplies, and LCR meters. By using these instruments they verified and deepened their understanding and the application of basic circuit theorems.

On the advanced circuit simulation techniques, the students learned how to use Multisim to create and simulate complex circuits. These students also learned how to use virtual oscilloscopes and other virtual instruments to obtain simulation results. They also learned how to use Multisim to conduct transient analysis, AC Sweep and DC Sweep analyses. These simulation experiments prepared these students to simulate the workings of new circuits that they would design in the future.

On the application of operational amplifiers, laboratory experiments were developed to demonstrate the benefits of operational amplifiers in small signal amplification, addition, subtraction, 
differentiation and integration. Techniques of conditioning a signal were also covered. Finally, the laboratory gave these students hands-on experience and practical knowledge of common applications such as frequency response, filtering, and transistor amplifiers. All these experiments should prepare them for their future laboratory and design courses.

\section{Bibliography}

[1] Y. Tsividis, A First Lab in Circuits and Electronics, Wiley, 2001.

[2] D. Kaplan and C.G. White, Hands-On Electronics: A Practical Introduction to Analog and Digital Circuits, Cambridge, 2003.

[3] C. Alexander and M. Sadiku, Fundamentals of Electric Circuits, 5 ${ }^{\text {th }}$ ed., McGraw-Hill, 2012.

[4] J. D. Irwin and R.M. Nelms, Basic Engineering Circuit Analysis, 8 ${ }^{\text {th }}$ ed., John Wiley, 2005.

[5] F.T. Ulaby and M.M. Maharbiz, Circuits, $2^{\text {nd }}$ ed., NTS, 2013. 
Appendix A: parts list

Each student was given the parts in the table below. The total price for all these parts was about $\$ 64.24$. Each student paid the lab fee of $\$ 75.00$ for this lab course. All the parts were budgeted within the lab fee and the unused lab fee could be used to provide spare parts.

\begin{tabular}{|c|c|c|c|}
\hline Product & Vendor Part \# & Description & Quantity \\
\hline $\begin{array}{l}\text { Continuity } \\
\text { checker }\end{array}$ & 3200CONCHK & soldering learning kit & 1 \\
\hline Resistor kit & $\underline{13 R K 5001}$ & 365 piece resistor kit & 1 \\
\hline Capacitor kit & 32ECOCAPKIT & capacitor kit economy & 1 \\
\hline $\begin{array}{l}\text { 50K Ohm } \\
\text { potentiometer }\end{array}$ & $\underline{18 S T X 50 K}$ & $\begin{array}{l}\text { 50K Ohm cermet potentiometer } \\
\text { single turn w knob }\end{array}$ & 1 \\
\hline $\begin{array}{l}\text { 10K Ohm } \\
\text { potentiometer }\end{array}$ & $\underline{18 S T X 10 K}$ & $\begin{array}{l}\text { 10K Ohm cermet potentiometer } \\
\text { single turn w knob }\end{array}$ & 1 \\
\hline $\begin{array}{l}\text { 1K Ohm } \\
\text { potentiometer }\end{array}$ & $\underline{18 S T X 1 K}$ & $\begin{array}{l}\text { 1K Ohm cermet potentiometer single } \\
\text { turn w knob }\end{array}$ & 1 \\
\hline Wire stripper & 60220 & Wire stripper - economy model & 1 \\
\hline Wire cutter & 60201 & $\begin{array}{l}\text { Crescent } 4.5 \text { " diagonal cutter with } \\
\text { channel lock }\end{array}$ & 1 \\
\hline Jumper wire kits & $\underline{2700 M J W 70}$ & Jumper wire kits for breadboarding & 1 \\
\hline Test lead set & 05ALS3 & 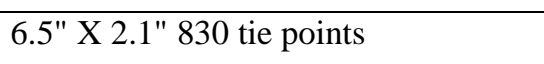 & 1 \\
\hline $\begin{array}{l}\text { BNC to IC test } \\
\text { hook }\end{array}$ & 05SPAT4 & $\begin{array}{l}\text { includes } 70 \text { piece jumper wire kit } \\
\text { with case }\end{array}$ & 1 \\
\hline $\begin{array}{l}\text { Banana to } \\
\text { alligator test lead }\end{array}$ & 05ALS8 & $\begin{array}{l}\text { Banana to alligator test lead set coax } \\
\text { cable }\end{array}$ & 1 \\
\hline Scope probe & 05SPAK220 & Scope probe set $60 \mathrm{MHz}$ & 1 \\
\hline $\begin{array}{l}\text { NPN transistor } \\
\text { 2N3904 }\end{array}$ & 112 N3904 & Transistors - NPN general purpose & 2 \\
\hline $100 \mathrm{mH}$ inductor & $150100 \mathrm{M}$ & Encapsulated R. F. chokes - 100 mH & 1 \\
\hline $150 \mathrm{mH}$ inductor & $150150 \mathrm{M}$ & Encapsulated R. F. chokes - 150 mH & 1 \\
\hline LED & 08L53GD & LED standard 5mm green & 1 \\
\hline Diode $1 \mathrm{~N} 4007$ & 1N4007FSCT-ND & diode general purpose 1KV 1A DO41 & 4 \\
\hline $\begin{array}{l}\text { Operational } \\
\text { amplifier }\end{array}$ & $\begin{array}{l}\text { LM741CNNS/NOPB- } \\
\text { ND }\end{array}$ & $\begin{array}{l}\text { IC operational amplifier 1.5MHZ } \\
\text { 8DIP }\end{array}$ & 3 \\
\hline
\end{tabular}


